\title{
Understanding Contextual Factors Effects and Their Implications for Italian Physiotherapists: Findings from a National Cross-Sectional Study
}

\author{
Mattia Bisconti ${ }^{1,2}$, Davide Venturin ${ }^{1,3, * \mathbb{D}}$, Alessandra Bianco ${ }^{1,4}$, Valentina Capurso ${ }^{5}$ and Giuseppe Giovannico ${ }^{1}$ \\ 1 Department of Medicine and Health Science "Vincenzo Tiberio", University of Molise, c/o Cardarelli \\ Hospital, C/da Tappino, 86100 Campobasso, Italy; mattia.bisconti@unimol.it (M.B.); \\ ft.alessandrabianco@gmail.com (A.B.); giuseppegiovannico73@gmail.com (G.G.) \\ 2 Physiotherapy and Manual Therapy, Physiotherapy Department UPMC Italy Salvator Mundi International \\ Hospital, Viale delle Mura Gianicolensi 67, 00152 Rome, Italy \\ 3 Kinè Physiotherapic Center, 31020 San Vendemiano, Italy \\ 4 Reha Medica, Centro Medico di Riabilitazione, 70014 Conversano, Italy \\ 5 Poliambulatorio San Luca, 70023 Gioia del Colle, Italy; valentinacapurso.12@gmail.com \\ * Correspondence: doc1028@studenti.unimol.it
}

check for updates

Citation: Bisconti, M.; Venturin, D.; Bianco, A.; Capurso, V.; Giovannico, G. Understanding Contextual Factors Effects and Their Implications for Italian Physiotherapists: Findings from a National Cross-Sectional Study. Healthcare 2021, 9, 689. https://doi.org/10.3390/ healthcare 9060689

Academic Editor: Tadashi Ito

Received: 2 May 2021

Accepted: 1 June 2021

Published: 7 June 2021

Publisher's Note: MDPI stays neutral with regard to jurisdictional claims in published maps and institutional affiliations.

Copyright: (c) 2021 by the authors. Licensee MDPI, Basel, Switzerland. This article is an open access article distributed under the terms and conditions of the Creative Commons Attribution (CC BY) license (https:// creativecommons.org/licenses/by/ $4.0 /)$.

\begin{abstract}
An online cross-sectional survey was conducted using Google Docs software. The aim was to understand the management of contextual factors and to identify which are most relevant and which clinicians underestimate. A total of 1250 physiotherapists were chosen from the database of the Manual Therapists group mailing list (GTM-IFOMPT MO) from July to August 2020. A total of 699 responses were received that were considered valid (56\%). Participants (40.83\%) identified contextual factors (CFs) as "any element, even involuntary, with which the patient interacts during treatment". Physiotherapists individually chose the representation of CF with the "therapeutic relationship" (82.9\%), followed by "therapeutic setting" (75.8\%). This choice differed between participants belonging to different age groups. Participants favor communication strategies (76.93\%). More than half $(57.88 \%)$ pay attention to patient involvement during the course of care; and in response to the patients' doubts about the use of treatments with limited scientific efficacy, they suggest different medical treatments. The patient's previous clinical experience is not considered significant and does not influence the choice of treatment. Subsequently, however, the participants reported that they stimulate the patients' positive expectations of the success of the clinical outcome $(45.27 \%)$. Knowledge of contextual factors in physiotherapy appears limited and very heterogeneous. Future research could increase the focus on professional development.
\end{abstract}

Keywords: contextual factors; context; pain management; Italian physiotherapists; placebo effects; nocebo effects

\section{Introduction}

Many reviews [1-4] and questionnaires [5-8] have highlighted the manner in which the therapeutic outcome is strongly influenced by the entire atmosphere surrounding the meeting between patient and healthcare professional $[2,4,9]$. The clinical condition of patients may change along with the treatment, worsening or improving without a particular expected evident reason [9]. This clinical phenomenon, in the current state of research, seems to be determined not only by the adequacy of the therapy adopted, but also by the way it is delivered [9]. The therapeutic arena, so called by Rossettini G., includes several elements such as therapeutic signs and rituals, the encounter between patient and physiotherapist, verbal and non-verbal interaction, the healthcare professional's appearance and behaviors, and patient expectations $[9,10]$. These features play a significant role during each clinical stage and are called contextual factors (CFs) [4,9]. By definition, CFs are all those physical, psychological, and social elements that distinguish any health encounter [1]. 
In physiotherapy, there are five CF categories: physiotherapist characteristics (i.e., professional reputation, appearance, beliefs, behaviors); patient's characteristics (i.e., expectations, preferences, previous experiences, musculoskeletal condition, gender, age); patient-physiotherapist relationship (i.e., verbal and non-verbal communication, therapeutic alliance); treatment (i.e., clear diagnosis, overt therapy, patient-centered approach, therapeutic touch), therapeutic environment (i.e., architecture, interior design, equipment) $[9,11]$.

Patients' exposure to a positive environment with positive CFs causes a placebo effect, resulting in improvement of symptoms (i.e., analgesia) [9]. A negative context, by contrast, could engender a nocebo effect, causing a worsening of the condition itself (i.e., hyperalgesia) [9]. The CFs affect not just pain, they also have a crucial role in motor performance and on overall patient satisfaction $[5,11]$. At the neurobiological level, CFs stimulate specific neurotransmitters (i.e., cholecystokinin, opioids, endocannabinoids, vasopressin and dopamine) that are responsible for significant clinical effects [5]. Furthermore, CFs can influence patients in different ways: the context responsiveness seems not to be continuous, but depends on the specific characteristics of the situation [6]. The patient is not always responsive to certain context elements: the same person, in similar contexts but different moments of their life, could respond in different ways [9].

In this scenario, we hypothesize that the distinct clinical success between two different healthcare professionals may depend on their ability to integrate contextual factors into clinical practice, while also both working according to scientific evidence and applying clinical guidelines. The available literature has reported the use of placebo effects in specific groups of healthcare workers in Europe, America and the Middle East. The literature documents their application by $17 \%$ and $80 \%$ of doctors, by $51 \%$ and $100 \%$ of nurses and by $52 \%$ of Italian OMPTs [5]. In contrast, the CFs knowledge and application by Italian physiotherapists are not yet available. The questionnaire survey aims, therefore, to understand how well the participants know the CFs, how often they use them and which CFs they prefer to apply. At this moment in history, such information should perforce belong to the clinicians' background to increase the success of their interventions.

This cross-sectional study starts from a literary review whose reference databases for the search strategy were PubMed, PEDro and Google scholar. A manual search was also performed, and only studies available in full-text in English were included. The strategy used for the literature research involved the combination of the following keywords and MESH terms: 〈Social Norms〉, 〈Cultural Competency〉, 〈Primary Health Care〉, 〈Placebo〉, 〈Nocebo〉,

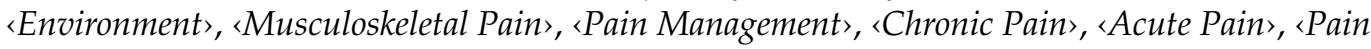
Perception〉, 〈Physiotherapy〉, 〈Clinical practice〉, 〈Contextual factors〉. Research has shown that in the last two decades, these issues have undergone a strong re-evaluation; however, many studies have focused on general medical practice, while few had a specific physiotherapy focus.

\section{Materials and Methods}

\subsection{Design and Ethical Issues}

Our research team issued a nationwide cross-cutting web-based survey following the Checklist for Reporting Results of Internet E-surveys (CHERRIES) [12] and Strengthening the Reporting of Observational Studies in Epidemiology (STROBE) [13]. It is a result of a project aimed at investigating the knowledge and governance of contextual factors ( $\mathrm{CFs}$ ) in clinical practice by Italian physiotherapists.

\subsection{Participants and Setting}

All respondents were Italian physiotherapists. The participation was voluntary, without compensation. A valid e-mail address and a Bachelor in physiotherapy were mandatory to complete the survey; it was not necessary to have any specialization. Respondents were required to be working, as a private physiotherapist or in a public healthcare service, in Italy when we made survey disclosure. 


\subsection{Instrument Questionnaire Development}

To improve the validity, formulation and clarity of the contents, two physiotherapists modified and implemented the first list of elaborated questions. They are lecturers at the University of Molise, and they are experts in musculoskeletal disorder rehabilitation and OMPT. During the preparation of the questionnaire, we pointed out the considered variables in order to clearly explain the suggested topics, the reason for the survey and the goals we aimed to achieve. Subsequently, we showed the paper to a Master of Science in Statistical Sciences, who further verified the reliability of the psychometric requirements in order to protect the accuracy of the obtained data before releasing the questionnaire. Compared to previous questionnaires with a similar purpose, in our survey, for the first time, each context factor (currently acknowledged) is individually studied [5-8]. The aim is to understand how to manage and identify the most relevant and underestimated CFs. Additionally, we focused on the region of Molise and regional Italian universities in order to determine any connection between CFs and education.

Once the preliminary version was ready, ten people received the questionnaire. They belonged to the determined target group, but they were not part of the project (seven highly experienced physiotherapists in clinical practice, two clinical physiotherapists and experts in survey design, and one statistician). These experts worked independently, identifying confusing or unclear questions and testing the length of the questionnaire [14]. Corrections were progressively included, taking into account their feedback.

The final version consisted of 25 critically evaluated questions for face and content validity [15]. Before they answered the questions, the system notified respondents that responses were anonymous, in accordance with the Legislative Decree 196/2003. The entry data were anonymous. We did not collect sensitive personal data. The attendees could agree to the use of their answers by the researchers only (by pressing the "next" button).

The questionnaire's preliminary page focuses on the presentation and methodological premise. Here we introduce the subject matter, name of the authors, estimated compiling time (about $7 \mathrm{~min}$ ) and purpose of the study.

The first section (section A) of the questionnaire gathers the sample's socio-demographic information. It consists of eight questions: five multiple-choice questions and three open questions. Section B explores the respondents' first approach to the topic. The additional sections $(n=7)$ are composed of multiple-choice questions. They have a logical sequence, and an initial title that indicates the context factor characteristic being studied in that section. The last one seeks to understand the respondents' opinions about delving into the subject matter within the context of the university training path. The response could be dichotomous (yes/ no). Google Forms (https:/ / www.google.it/intl/it/forms/about/) (accessed on 30 June 2020) was the chosen platform for data collection and online management. The complete original questionnaire is attached.

\subsection{Data Collection Instrument and Process}

Our team released the questionnaire on 1 July 2020, and it was available until August 24, 2020. The participants received a Google Forms invitation link (see Supplementary Materials). The team shared the link with 1250 physiotherapists who were Group of Manual Therapists mailing list subscribers (GTM). An introductory message to the link described the growing interest in the topic.

\subsection{Data Analysis}

Google Modules automatically imported the respondents' answers into an Excel document immediately after completion of the survey. The system deleted incomplete answers and duplicates. R codes detected obvious weak responses [16]. Google Forms saved data in the format .xlsx.

For questions with one answer, our team applied descriptive statistics: mathematical average and standard deviation (SD). The software statistically calculated continuous vari- 
ables and confidence intervals (CI) 95\%. The system assigned frequencies and percentages to dichotomous, nominal and ordinal variables.

For questions with multiple-choice answers, the software calculated the absolute and relative frequencies for each answer combination. The Cramer V index [17] examined the association between individual characteristics (section $\mathrm{A}$ ) and single-choice responses (sections B, C, D, E, F, G, H).

The system transformed the participants' age and the years of career into ordinal variables. The analysis of the correlations consisted of dividing these into five and four different classes (as described below in Tables 1-8), respectively. The acceptance threshold for correlation values was higher than 0.60 . $R$ software [16] and the psych [18] and ggplot2 [19] packages were used to examine the data.

\section{Results}

Seven hundred and four physiotherapists replied to the online questionnaire. We deemed five questionnaires invalid due to insubstantial answers (non-existent universities/schools and/or disproportionate time taken to obtain the qualification). No questionnaire was incomplete. The remaining 699 questionnaires (99.2\%) were deemed valid for the data analysis.

\subsection{Demographic Characteristics of Participants (SECTION A)}

The majority of the participants ( $\mathrm{n}=385 ; 55 \%$; $95 \%$ CI 55.09-55.23) are male with an average age of 32 years. The sample is composed of five five-year age groups (from 20 to 40) with the open final class $(40+)$. We observe that the respondents belong mainly to the 26-30 group of age (36.82\%), followed by the 31-35 group (20.20\%). The youngest graduates are between 21 and 25 years old (17.34\%). The two over- 40 s groups comprise $25.64 \%$ (36-40 and over 40 ). The average years of work experience are 8.7 . A total of $36.96 \%(n=258,95 \%$ IC, 233.4-283.4) of respondents have less than 5 years of experience. A smaller number of respondents have $10-20$ years of work experience (16.91\%, $n=118,95 \%$ IC 98.7-137.6). The number of respondents with more than 20 years of work experience is just as small $(9.74 \% \mathrm{n}=6895 \% \mathrm{IC}, 52.7-83.5)$. A total of $70 \%$ ( $40 \%$ men and $30 \%$ women) of respondents work in private practice $(\mathrm{n}=489 / 699,95 \%$ IC $466-513.4)$. A total of $20 \%(\mathrm{n}=139,95 \%$ CI $118.5-159.9)$ work in private facilities. Only $8 \%(n=58,95 \%$ CI $43.8-72.4)$, mostly female, work in a public facility. The remaining $1.72 \%(n=12,95 \%$ IC 5.3-18.8) work in universities with different job roles.

A total of $49.57 \%$ of the physiotherapists ( $n=346,95 \%$ IC 320-372.4) work in Northern Italy and $46.42 \%(n=324$, IC $298-350)$ graduated there as well. A total of $38.12 \%$ of the physiotherapists ( $\mathrm{n}=266,95 \%$ CI 241.2-291.5) currently work in Southern Italy. Of those, $38.97 \%$ of them $(n=272,95 \%$ IC $247.1-297.7)$ graduated in southern Italian regions. The remaining $12.32 \%(\mathrm{n}=86,95 \%$ IC $69.1-103.2)$ work in central Italian regions, and $14.61 \%$ of them ( $n=102,95 \%$ IC 83.8-120.5) received their Bachelor in these regions.

\subsection{Knowledge and Management of Contextual Factors (SECTION B)}

Our team researched where the participants heard about $\mathrm{CFs}$ for the first time. A total of $33.95 \%(n=237,95 \%$ IC 212.8-261.9) reported having become aware of them during the 1st cycle degree program. The most frequently reported universities were: University of Ferrara (74\%), Sacred Heart Catholic University of Rome (50\%), University of Padua $(47.7 \%)$, University of Genoa (47.2\%).

The majority of the participants-40.83\% ( $\mathrm{n}=285,95 \%$ IC 259.9-310.9)—consider CFs "any element voluntary and involuntary, with which the patient interacts during the treatment". A total of $16.33 \%(\mathrm{n}=114,95 \%$ IC $95-133.3)$ selected answers 1 and 2 . A total of $9.89 \%$ $(\mathrm{n}=69,95 \%$ IC 53.6-84.6) selected answers 1 and 3.

All of the remaining nine combinations received a total number of answers equal to $15 \%$, with the combination of the first three answers having $4.30 \%(n=30,95 \%$ IC $19.5-40.6)$. The remainder did not exceed $2.01 \%$ per response. (Figure 1). 
A total of $82.9 \%$ ( $n=583,95 \%$ IC, 561.4-600.3) of the participants chose the representation of the CFs connected with the therapeutic relationship. A total of $75.8 \%$ ( $n=533,95 \%$ IC, 506.5-551) chose the therapeutic setting. Only $36.82 \%(n=257,95 \%$ IC, $232.4-282.4)$ chose all five answers in the representation of CFs (patient characteristics, physiotherapist characteristics, treatment characteristics, therapeutic setting, therapeutic relationship). The remaining $5.87 \%$ of the respondents chose the answers that include the therapeutic relationship and the therapeutic setting $(n=41)$ (Figure 2).
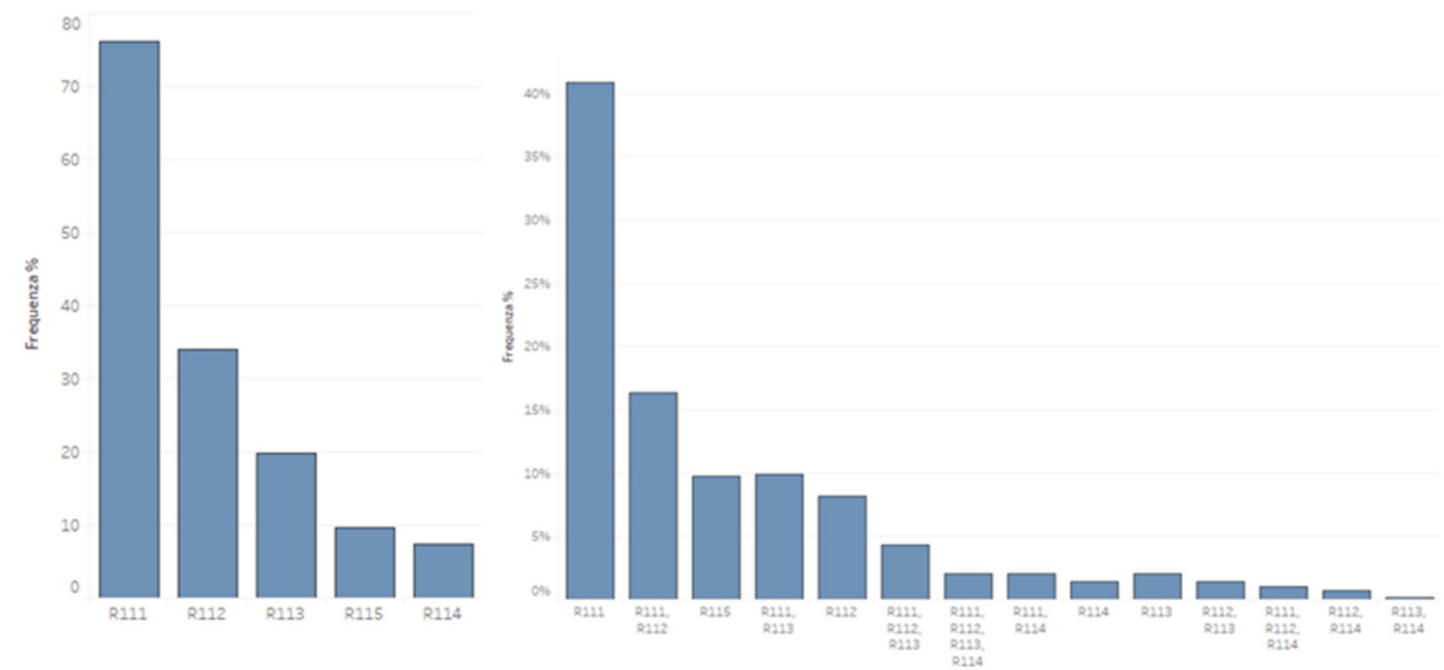

Figure 1. Single and multiple answers. \% percentages of module 1 response count for each D1,D11: What are CFs; (R111) any element, voluntary and involuntary, with which the patient interacts during the treatment; (R112) specific therapeutic tool that influences the outcome of the treatment through neurophysiological mechanisms; (R113) intervention without a specific effect but with a possible non-specific effect; (R114) diagnostic tool that distinguishes a psychological-type problem from an organic-type problem; (R115) I can't define it.

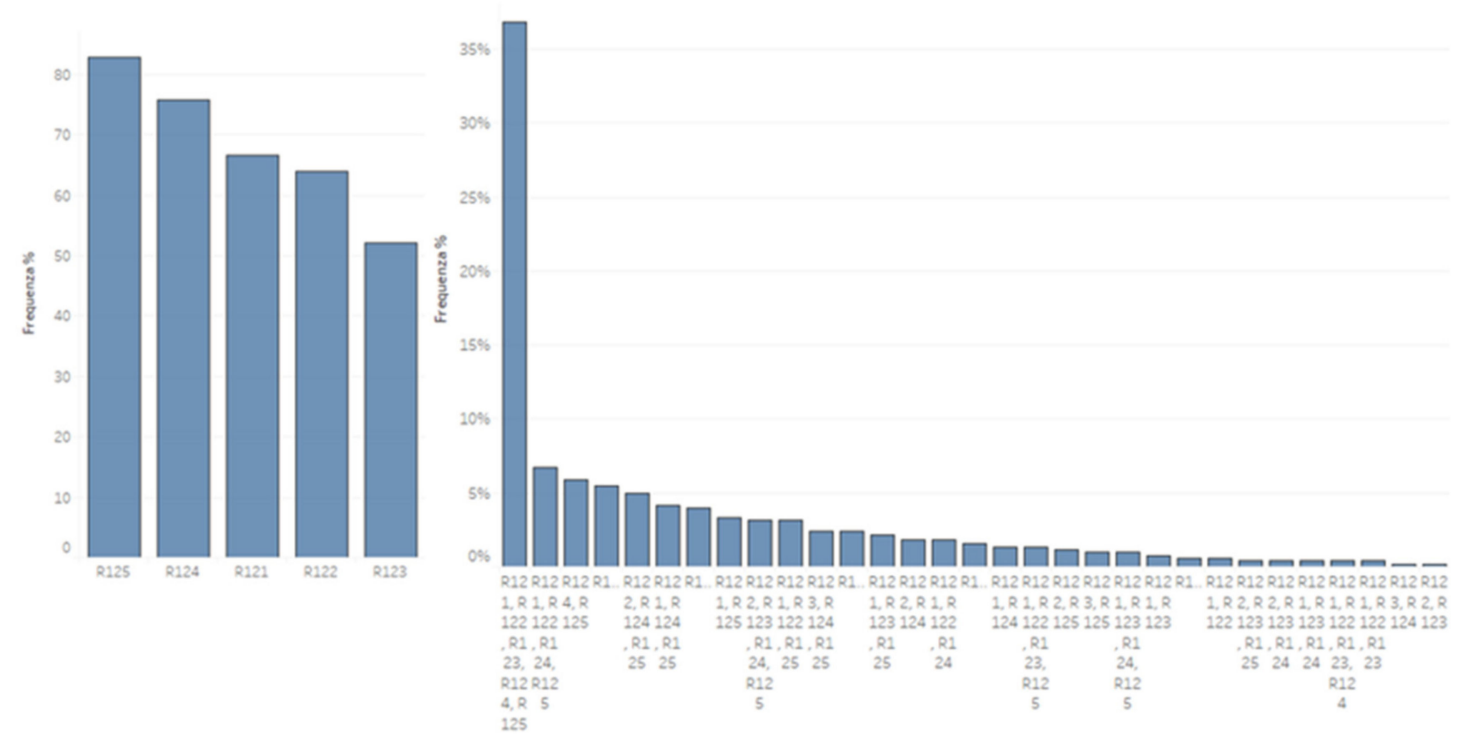

Figure 2. Single and multiple answers. \% percentages of module 1 response count for each D1, D12: Which of these do you think represents a CF? (R121) patient characteristics; (R122) physiotherapist characteristics; (R123) treatment characteristics; (R124) Therapeutic environment; (R125) patient-physiotherapist relationship.

Most participants, $57.16 \%(\mathrm{n}=399,95 \%$ IC $373-425.2)$, in clinical practice pay more attention to the therapeutic relationship. 
The majority of the participants, 54.4\% $(n=380,95 \%$ IC 354.7-406.4), find it more useful to know how to manage contextual factors to improve the clinical response to physiotherapy treatment. A Likert scale examined the frequency of the use of CFs in clinical practice. Values ranged between " 1 " and " 5 ". " 1 " indicates a minimal use of CFs and " 5 " stands for greater use of CFs. The detected frequency seems to be relatively high, with an average of 3.7 (1095 DS).

\subsection{Physiotherapist Characteristics (SECTION C)}

A total of $76.93 \%(n=537,95 \%$ IC $515.9-559.6)$ of the physiotherapists lend great importance to communication strategies in order to achieve better therapeutic results. A total of $15.76 \%(n=110,95 \%$ CI 91.3-129) indicated that the best results arise from professional reputation.

The questionnaire examined the case in which a patient asks about the use of medical treatments, the effectiveness of which is without scientific evidence. A total of $50.29 \%$ ( $\mathrm{n}=351,95 \%$ IC $325.6-377.4$ ) of the sample offer a different treatment that is more suitable for the clinical situation.

\subsection{Patient Characteristics (SECTION D)}

Our team examined the physiotherapists' method of working with respect to the patient's experience with other treatments and different professionals. A total of $44.70 \%$ ( $n=312,95 \%$ IC 286.7-335.2) believe that previous experiences do not affect the treatment.

The participants indicated that they stimulate the patient's positive expectations, aiming at the success of the therapeutic management $(45.27 \%, n=316,95 \%$ IC $290.7-$ 342.2). Otherwise, the physiotherapists take into account the patient's expectations due to the influence these have on the outcome of the treatment $(39.97 \%, \mathrm{n}=279,95 \%$ CI 254 304.8). The survey analyzed the clinical approach according to the patient demographic characteristics. A total of $67.48 \%(n=471,95 \%$ IC $447.4-495.9)$ of the physiotherapists adapt their treatment depending on the patients' age and gender.

\subsection{Patient-Physiotherapist Relationship (SECTION E)}

Physiotherapists attribute value to the relationship with the patient, with $57.88 \%$ ( $n=404,95 \%$ IC 379-430.2) of the participants corresponding with the patient during the treatment path. Next in order of importance were the communicative aspect, willingness to adapt to the patient's demands, and the therapeutic touch. Concerning the real communication with the patient, the most significant element, identified by $36.25 \%$ ( $n=253,95 \%$ IC 228.5-278.3) of the physiotherapists, is active listening.

\subsection{Treatment Characteristics (SECTION F)}

With respect to the elements most taken into account during therapeutic planning, $54.87 \%$ ( $n=383,95 \%$ IC 357.8-409.3) of the participants believe it is essential to plan the sessions according to the patient's clinical condition. Only $3.15 \%(n=22,95 \%$ IC $13-31.1)$ believe that group sessions are relevant for patients with similar problems. A total of $40.69 \%$ ( $n=284,95 \%$ IC 259-309.9) of respondents claim that the price of the service is standard. Only $2.44 \%(n=1795 \%$ IC 9-25) of the participants determine the cost depending on the prescribed brand's therapy.

\subsection{Therapeutic Environment (SECTION G)}

Of the participants, $57.59 \%(\mathrm{n}=402,95 \%$ IC 377-428.2) promote the therapeutic context by focusing on general comfort (natural lighting, ventilation, heating, etc.). The next most frequent elements are: environmental design, and next-gen equipment. 


\subsection{Conclusions (SECTION H)}

For $96.42 \%(n=673,95 \%$ IC $664.3-683.6)$ of respondents, the contextual factors are significant and the study of their application should be deepened during training. Only $3.58 \%(\mathrm{n}=25,95 \%$ IC 15.4-34.7) do not consider contextual factors relevant.

A comprehensive analysis of the questionnaire answers is provided in detail in Tables 1-8.

\section{Tables and Schemes}

Table 1. Participant's characteristics $(n=699) . \%$ : percentage, $n$ : number of participants, $95 \%$ IC: $95 \%$ confidence interval.

\begin{tabular}{|c|c|c|}
\hline Gender & Values & $95 \%$ CI \\
\hline Men, n (\%) & $385(55.0)$ & $55.09-55.23$ \\
\hline Women, n (\%) & $314(45.0)$ & $287.7-339.2$ \\
\hline \multicolumn{3}{|l|}{ Years, average (SD) } \\
\hline $21-25, \mathrm{n}(\%)$ & $121(17.34)$ & \\
\hline $26-30, \mathrm{n}(\%)$ & $257(36.82)$ & \\
\hline $31-35, \mathrm{n}(\%)$ & $141(20.20)$ & \\
\hline $36+, \mathrm{n}(\%)$ & $179(25.64)$ & \\
\hline \multicolumn{3}{|l|}{ Job Title } \\
\hline Freelancer, n (\%) & $489(70)$ & $466-513.4$ \\
\hline Private facility $\mathrm{n}(\%)$ & $139(20)$ & $118.5-159.9$ \\
\hline Public facility, n (\%) & $58(8)$ & $43.8-72.4$ \\
\hline University professor, n (\%) & $1(0.1)$ & $0-3$ \\
\hline $\begin{array}{c}\text { Post-graduate studies (master) } \\
\text { professor } n(\%)\end{array}$ & $8(1.5)$ & $2.5-13.5$ \\
\hline $\begin{array}{l}\text { Private courses or studies } \\
\text { post-graduate professor, n (\%) }\end{array}$ & $3(0.4)$ & $0-6.4$ \\
\hline Researcher, n (\%) & $0(0)$ & 0 \\
\hline \multicolumn{3}{|l|}{ Work field } \\
\hline Musculoskeletal, n (\%) & $507(72.64)$ & $484.6-530.8$ \\
\hline Neurological, n (\%) & $73(10.46)$ & $57.2-89$ \\
\hline Geriatric, n (\%) & $63(9.03)$ & $48.2-77.9$ \\
\hline Sports n $(\%)$ & $33(4.7)$ & $22-44$ \\
\hline Cardiorespiratory, n (\%) & $22(3.15)$ & $13-31.1$ \\
\hline None of the above $n(\%)$ & $0(0)$ & 0 \\
\hline \multicolumn{3}{|l|}{ Working Italian region } \\
\hline North, n (\%) & $346(49.57)$ & $320-372.4$ \\
\hline Center, n (\%) & $86(12.32)$ & $69.1-103.2$ \\
\hline South, n (\%) & $266(38.12)$ & $241.2-291.5$ \\
\hline \multicolumn{3}{|l|}{ Participants' graduation } \\
\hline \multicolumn{3}{|l|}{ Italian region } \\
\hline North, n (\%) & $324(46.42)$ & $298-350$ \\
\hline Center, n (\%) & $102(14.61)$ & $83.8-120.5$ \\
\hline South, n (\%) & 272 (38.97) & 247.1-297.7 \\
\hline \multicolumn{3}{|l|}{ University } \\
\hline North, (\%) & 46.42 & \\
\hline Center, $(\%)$ & 14.61 & \\
\hline South, (\%) & 38.97 & \\
\hline
\end{tabular}


Table 2. Contextual factors (CFs). \%: percentage, n: number of participants, 95\% IC: 95\% confidence interval.

\begin{tabular}{|c|c|c|}
\hline Environment in Which You Heard of CFs for the First Time & Values & $95 \% \mathrm{CI}$ \\
\hline Bachelor's degree, n (\%) & $237(33.95)$ & $212.8-261.9$ \\
\hline Master, n (\%) & $190(27.22)$ & $167.2-213.3$ \\
\hline Never heard & $111(15.90)$ & $92.2-130.1$ \\
\hline about CFs, n (\%) & & $85.7-122.6$ \\
\hline Private course, $\mathrm{n}(\%)$ & $104(14.90)$ & $32.3-57.8$ \\
\hline Social media, $\mathrm{n}(\%)$ & $45(6.45)$ & $4.6-17.5$ \\
\hline Magistral degree, $\mathrm{n}(\%)$ & $11(1.58)$ & \\
\hline \multicolumn{3}{|l|}{ What the CFs are } \\
\hline $\begin{array}{c}\text { Any element, voluntary or involuntary, with which the patient interacts during } \\
\text { treatment, } \mathrm{n}(\%)\end{array}$ & $536(76.2)$ & $514.9-558.6$ \\
\hline $\begin{array}{l}\text { Specific therapeutic tool able to influence the treatment outcome through } \\
\text { neurophysiological mechanisms, } \mathrm{n}(\%)\end{array}$ & $239(34)$ & $214.8-263.9$ \\
\hline Intervention without a specific effect but with a possible non-specific effect, n (\%) & $140(19.9)$ & $119.5-161$ \\
\hline $\begin{array}{c}\text { Diagnostic tool capable of distinguishing between a psychological problem and an } \\
\text { organic problem, } \mathrm{n}(\%)\end{array}$ & $51(7.3)$ & $37.6-64.6$ \\
\hline I don't know how to describe it, $\mathrm{n}(\%)$ & $68(9.74)$ & $52.7-83.5$ \\
\hline \multicolumn{3}{|l|}{ The CF considered most important } \\
\hline Patient characteristics, n (\%) & $168(24.07)$ & $146.1-190.4$ \\
\hline Physiotherapist characteristics, $\mathrm{n}(\%)$ & $20(2.87)$ & $11.4-28.7$ \\
\hline Treatment characteristics, $\mathrm{n}(\%)$ & $84(12.03)$ & $67.3-101$ \\
\hline Therapeutic setting, $\mathrm{n}(\%)$ & $27(2.87)$ & $17-37$ \\
\hline Therapeutic relationship, $\mathrm{n}(\%)$ & $399(57.16)$ & $373-425.2$ \\
\hline \multicolumn{3}{|l|}{ Usefulness of their knowledge } \\
\hline Improve the therapeutic relationship, $\mathrm{n}(\%)$ & $144(20.63)$ & $123.2-165.2$ \\
\hline Improve the clinical response to physiotherapy treatment, $\mathrm{n}(\%)$ & $380(54.4)$ & $354.7-406.4$ \\
\hline Improve the patient's satisfaction, $\mathrm{n}(\%)$ & $166(23.78)$ & $144.2-188.3$ \\
\hline Control symptoms, $\mathrm{n}(\%)$ & $8(1.15)$ & $2.5-13.5$ \\
\hline
\end{tabular}

Table 3. Frequency of use CFs.

\begin{tabular}{|c|c|c|c|c|c|c|}
\hline $\begin{array}{c}\text { Frequency of } \\
\text { use of CFs }\end{array}$ & $\begin{array}{c}\text { Likert Score } \\
\text { Average }\end{array}$ & $\begin{array}{c}1 \text { (Never) } \\
\text { n (\%), } 95 \% \text { IC }\end{array}$ & $\begin{array}{c}2(\text { Few) } \\
\text { n (\%), 95\% IC }\end{array}$ & $\begin{array}{c}3 \text { (Sometimes) } \\
\text { n (\%), } \\
95 \% \text { IC }\end{array}$ & $\begin{array}{c}4 \text { (Often) } \\
\text { n (\%), } \\
95 \% \text { IC }\end{array}$ & $\begin{array}{c}5 \text { (Always) } \\
\text { n (\%), } \\
95 \% \text { IC }\end{array}$ \\
\hline & 3.7 & $\begin{array}{l}34 .(4.87) \\
22.9-45.2\end{array}$ & $\begin{array}{l}45 .(6.45) . \\
32.3-57.8\end{array}$ & $\begin{array}{l}\text { 171. (24.5). } \\
149-193.5\end{array}$ & $\begin{array}{l}236 .(33.81) \\
211.8-260.9\end{array}$ & $\begin{array}{l}\text { 212. (30.37) } \\
188.5-236.1\end{array}$ \\
\hline
\end{tabular}

Table 4. Physiotherapist characteristics, \%: percentage, n: number of participants, 95\% IC: 95\% confidence interval.

\begin{tabular}{|c|c|c|}
\hline Most Important Professional Personal Element & Values & $95 \% \mathrm{CI}$ \\
\hline Professional reputation $\mathrm{n}(\%)$ & $110(15.76)$ & $91.3-129$ \\
\hline Uniform n $(\%)$ & $9(1.29)$ & $3.2-14.9$ \\
\hline Hygiene and cleanliness, $\mathrm{n}(\%)$ & $35(5.01)$ & $23.7-46.4$ \\
\hline Communication strategies, $\mathrm{n}(\%)$ & $537(76.93)$ & $515.9-559.6$ \\
\hline Charge, $\mathrm{n}(\%)$ & $7(1.00)$ & $1.8-12.2$ \\
\hline \multicolumn{3}{|l|}{ Strategy adopted in front of a request for treatment not scientifically proven } \\
\hline Provide the requested therapy by the patient while aware of its ineffectiveness, $n(\%)$ & $52(7.45)$ & $38.5-66.7$ \\
\hline Inform the patient about inappropriate therapy; $\mathrm{n}(\%)$ & $224(32.09)$ & $200.1-248$ \\
\hline $\begin{array}{l}\text { Suggest a different treatment that reflects your beliefs, knowledge and experience about } \\
\text { the clinical picture; } \mathrm{n}(\%)\end{array}$ & $351(50.29)$ & $325.6-377.4$ \\
\hline Suggest the requested therapy, but only after the previous provided therapy fails, $\mathrm{n}(\%)$ & $71(10.17)$ & $55.4-86.8$ \\
\hline
\end{tabular}


Table 5. Patient characteristics, \%: percentage, n: number of participants, 95\% IC: $95 \%$ confidence interval.

\begin{tabular}{|c|c|c|}
\hline Influence of Past Experiences on the Therapeutic Strategy & Values & $95 \% \mathrm{CI}$ \\
\hline $\begin{array}{l}\text { Perform the therapeutic strategy adopted by the previous healthcare professional because it is } \\
\text { beneficial to the patient, even if not supported by scientific evidence, } n(\%)\end{array}$ & $104(14.90)$ & $85.7-122.6$ \\
\hline $\begin{array}{l}\text { Do not perform therapy deemed most appropriate and suitable for the patient if he reports } \\
\text { negative experiences in the past, } \mathrm{n}(\%)\end{array}$ & $245(35.10)$ & $220.06-270.01$ \\
\hline Previous experiences do not affect the choice of the treatment at that the time, $\mathrm{n}(\%)$ & $312(44.70)$ & $286.7-335.2$ \\
\hline Always comply with my patient's request $\mathrm{n}(\%)$ & $37(5.30)$ & $25.4-48.7$ \\
\hline \multicolumn{3}{|l|}{ Management strategy and patient expectations } \\
\hline The patient's expectations do not influence the treatment, $\mathrm{n}(\%)$ & $25(3.58)$ & $15.4-34.7$ \\
\hline $\begin{array}{c}\text { Take into account the patient expectations because they may affect the treatment outcome } \\
\text { regardless of the specificity of it, } n(\%)\end{array}$ & 279 (39.97) & 254-304.8 \\
\hline $\begin{array}{l}\text { Always try to stimulate positive expectations in order to strengthen motivation, therapeutic } \\
\text { alliance and clinical outcome, } \mathrm{n}(\%)\end{array}$ & $316(45.27)$ & $290.7-342.2$ \\
\hline $\begin{array}{l}\text { Try to mitigate negative expectations (based on information gaps) by explaining, before the } \\
\text { treatment, the proven effectiveness of the chosen strategy, } \mathrm{n}(\%)\end{array}$ & $78(11.17)$ & $61.8-94.4$ \\
\hline \multicolumn{3}{|l|}{ Management strategy and patient's age and gender } \\
\hline Always adapted clinical practice to patient's age and gender & $471(67.48)$ & $447.4-495.9$ \\
\hline Patient's gender and age does not influence the treatment choice, $\mathrm{n}(\%)$ & $17(2.44)$ & $9-25$ \\
\hline $\begin{array}{l}\text { Believe it is necessary to make a distinction but I do not know how to adapt my clinical } \\
\text { practice, } \mathrm{n}(\%)\end{array}$ & $51(7.31)$ & $37.6-64.6$ \\
\hline Different approach depending on patient's age, but I do not believe gender is relevant, $\mathrm{n}(\%$ & $159(22.78)$ & 137.5-181 \\
\hline
\end{tabular}

Table 6. Patient-physiotherapist relationship. \%: percentage, n: number of participants, 95\% IC: $95 \%$ confidence interval.

\begin{tabular}{|c|c|c|}
\hline Most Important Relational Element & Values & $95 \%$ IC \\
\hline Communication, $\mathrm{n}(\%)$ & $215(30.8)$ & $191.4-239.2$ \\
\hline Availability in front of the patient's requests, $\mathrm{n}(\%)$ & $47(6.67)$ & $34.1-60.1$ \\
\hline Patient-centered care pathway, n (\%) & $404(57.88)$ & $379-430.2$ \\
\hline Therapeutic touch, $\mathrm{n}(\%)$ & $32(4.58)$ & $21.2-42.9$ \\
\hline \multicolumn{3}{|l|}{ Key element of communication } \\
\hline Active listening, $\mathrm{n}(\%)$ & $253(36.25)$ & $228.5-278.3$ \\
\hline Use of technical speech, n (\%) & $4(0.57)$ & $0.1-7.9$ \\
\hline Verbal expressions of support and encouragement, $\mathrm{n}(\%)$ & $62(8.8)$ & $47.3-76.8$ \\
\hline Humor and sympathy, $\mathrm{n}(\%)$ & $28(3.8)$ & $17-37$ \\
\hline Paraphrases, images and metaphors to help the patient understand his medical condition, $\mathrm{n}(\%)$ & $176(25.21)$ & 153.7-198.8 \\
\hline Explanation of the effects and treatment execution (overt therapy), $\mathrm{n}(\%)$ & $97(13.9)$ & $79.2-115.1$ \\
\hline Consistency between verbal, paraverbal and non-verbal language, $\mathrm{n}(\%)$ & $79(11.30)$ & $62.7-95.5$ \\
\hline
\end{tabular}

Table 7. Treatment characteristics. $\%$ : percentage, $\mathrm{n}$ : number of participants, $95 \%$ IC: $95 \%$ confidence interval.

\begin{tabular}{|c|c|c|}
\hline Elements Taken into Account during Planning & Values & $95 \%$ IC \\
\hline Priority for one-to-one session, n (\%) & $232(33.24)$ & $207.9-256.7$ \\
\hline Group session for patients with similar problems, n (\%) & $22(3.15)$ & $13-31.1$ \\
\hline Patient's availability, n (\%) & $61(8.74)$ & $46.5-75.5$ \\
\hline Patient's clinical status, n (\%) & $383(54.87)$ & $357.8-409.3$ \\
\hline \multicolumn{3}{|l|}{ Price of treatments } \\
\hline $\begin{array}{l}\text { Better branded therapies have } \\
\text { a higher cost, } \mathrm{n}(\%)\end{array}$ & $17(2.44)$ & $9-25$ \\
\hline The price depends on the time spent during the session, $\mathrm{n}(\%)$ & $114(16.33)$ & $95-133.3$ \\
\hline $\begin{array}{l}\text { The price depends on the treatment type (innovations, } \\
\text { advanced technology, etc.), } \mathrm{n}(\%)\end{array}$ & $125(17.91)$ & $105.3-145$ \\
\hline The price depends on the treatment complexity, $\mathrm{n}(\%)$ & $119(17.05)$ & $99.7-138.7$ \\
\hline The price depends on the clinician experience, $\mathrm{n}(\%)$ & $39(5.59)$ & $27.2-51$ \\
\hline The treatment price is standard, $\mathrm{n}(\%)$ & $284(40.69)$ & 259-309.9 \\
\hline
\end{tabular}


Table 8. Therapeutic environment. \%: percentage, n: number of participants, $95 \%$ IC: $95 \%$ confidence interval.

\begin{tabular}{ccc}
\hline Therapeutic Environment Care & Values & 95 \% IC \\
\hline Setting design, $\mathrm{n}(\%)$ & $172(24.64)$ & $149.9-194.6$ \\
\hline Technological equipment, $\mathrm{n}(\%)$ & $31(4.44)$ & $20.4-41.7$ \\
\hline Architecture to respect privacy, $\mathrm{n}(\%)$ & $93(32)$ & $75.5-110.7$ \\
\hline General comfort, $\mathrm{n}(\%)$ & $402(57.59)$ & $377-428.2$ \\
\hline
\end{tabular}

\section{Discussion}

This survey is the first national one researching Italian physiotherapists' knowledge and use of CFs. The main achievement of this study is to prove that participants are aware of context-related effects in their clinical practice. These effects can be triggered by specific characteristics of the intervention provided and by non-specific characteristics not inherent to it. However, some potentially significant aspects are still underestimated. According to our research, most Italian physiotherapists deem CFs to be any element, even unintentional ones, with which the patient interacts during treatment. In previous OMPT surveys $[5,20]$, instead, the results revealed that physiotherapists regarded them as random elements. Few considered them to be a specific therapeutic tool capable of influencing patients' clinical outcomes $[5,9,11]$. This point of view may be related to limited knowledge regarding the neurophysiological mechanisms behind the therapeutic effects of CFs $[1,21,22]$. Several participants stated having learned about CFs during a 2nd cycle degree class. The lower attendance among the participants of 2nd cycle degree courses may have affected this response. This may depend on how the Italian institutional system configures physiotherapists' career path. In line with most studies, Italian physiotherapists identify the contextual factor "therapeutic relationship" as the essential element for fair clinical success [9]. While it is true that the therapeutic alliance is known as an outcome predictor during musculoskeletal physical therapy [23], this result does not justify the small percentage of participants who believe it is significant to improve the "characteristics of the physiotherapist" in order to achieve the same result. It is clear now that the patient's perception of the physiotherapist- their qualifications and reputation, the way they dressmay influence the overall perceptions of the patient $[9,11]$. In detail, by questioning the participants about the specific tools available to them (aiming to increase the probability of success), we came across communication strategies, followed by professional reputation. Professional reputation was the element that received the second-most feedback, unlike other surveys on the same topics [7]. However, the majority of the sample barely use this $\mathrm{CF}$ and do not value it to be significant. This may be due to a particular lack of knowledge of its clinical relevance and the complex concept of professional identity [5]. This is also confirmed by the low percentage of participants who opted for the use of a uniform as a feature for enhancing the therapeutic result.

We observed that, according to different age groups, the usage of CFs varies. Most respondents belonging to the 26-30 age group selected the answer "physiotherapist-patient relationship" as a first choice. The 36-40-year-old group pays attention more to the patient's characteristics. The clinicians' age relative to their years of work shows that experience leads clinicians to pay more attention to the patient than to their relationship with them. They take into account the patient's overall characteristics in many ways: gender, age, expectations and previous experiences. In situations where a patient desires a treatment whose efficacy lacks available scientific evidence, half of the respondents suggest a different treatment that is more suitable for the clinical picture. This specific question underlines a hotly debated topic: providing the best therapy in terms of scientific evidence without forgetting internal elements (i.e., expectations and previous experiences) that may have a significant effect $[2,9,11,24,25]$. As suggested by the current literature, physiotherapists who decide to advise a different treatment, regardless of the patient's demands, should carefully balance the positive characteristics of medical treatment with the negative ones 
of the other [26]. Behind this, there is a significant aspect of the therapeutic relationship: the sharing of decision making [27-29]. If there are two treatment options, one desired by the patient and one deemed most appropriate by the therapist, the shared decisionmaking process could change the patient's belief. The patient transitions from uninformed preferences to better-explained preferences $[27,28,30]$. Physiotherapists that prescribe a treatment without scientific proof and do not inform their patients are adopting a nontransparent and misleading communication. This disrespects the ethical principles behind a prescribed therapy (i.e., the principle of autonomy; informed consent) $[27,28,30]$.

The patient's past experiences with previous healthcare professionals are not considered to be a factor influencing the therapeutic choice pursued. This result is very different from current evidence showing that associative learning and past experiences lead to mechanisms of action underlying the nocebo and placebo effect $[9,29,31]$. Redundant therapy associations with some of its characteristics (i.e., color, smell, shape, invasiveness, etc.) and associations with verbal messages that arouse expectations (i.e., this therapy will decrease your pain) may activate context-related effects in healthy people and patients $[11,32,33]$. The spread of positive expectations can modify subjective results (i.e., pain and anxiety) and objective results (feature and disability) in patients suffering from musculoskeletal pain [32,34].

The Italian physiotherapists, when questioned on the management of the demographic characteristics, claim to take into account age, but do not always consider gender. This variable plays a significant role in clinical practice $[35,36]$. The patient may experience pain or behave differently in response to it. Gender and age can also affect how people interpret pain or the behavior of other people [37-39]. Women tend to show and experience more pain than men. Men, instead, consider themselves more determined and more focused on objectives [37]. Since men value themselves as being more determined, it may suggest that when it comes to making decisions about diagnosis or case management, physiotherapists should rely more on these aspects. Men seem to value result-oriented communication. By contrast, too much determination may come across as paternalistic or not very sympathetic for the female gender [40]. Understanding these characteristics could be useful for improving interactions with patients and generating future lines of research for those who believe that these factors are relevant, but do not know how to develop them or, on the contrary, for those who believe that gender has no impact on treatment choice.

Regarding the "treatment characteristics", the patient's engagement with their treatment path is considered by participating physiotherapists to be a result of improved self-efficacy and self-responsibility in patients with musculoskeletal pain $[9,35,41]$. Therapeutic touch, on the other hand, is a relational element that is rarely taken into account. A profession that spends such a large amount of time with patients should understand that it is possible to deliver positive and negative messages, specifically through touch [11,42]. The participants also believe that the explanation of treatment effects and performance (overt therapy) are less influential CFs. Physiotherapists have little practical knowledge of their clinical relevance. Different surveys on the same topic indicate that patients greatly appreciate this element, and therefore clinicians should take it into consideration more often [7].

Overall, our results suggest to physiotherapists the need to consider communicationspecific CFs as triggers of placebo and nocebo effects capable of having a considerable impact on patient outcomes, in accordance with the evidence reported in the fields of medicine and physiotherapy [22,43]. Seeing how physiotherapists plan the therapy, it seems that Italians tend to underestimate the effect of positive social interactions. Positive interactions could arise from contact with patients with a similar medical history. On the contrary, they prefer to choose one-to-one sessions. The literature shows how patients who support each other's efforts to improve the health make the environment more motivating. They also develop supportive relationships and emotional support $[44,45]$. With respect to the reasons for the price of the service provided, there was a difference between the different age groups. The 20-36 age group claimed that the price of the session depends 
on the time spent. Other age groups reported a standard price, regardless of different recommended variables (i.e., brand, complexity, experience). The current literature does not include articles about the analysis of this field, but we know it is one of the factors influencing patients' choices, and further investigation is required to study this aspect and to validate the investigation.

Italian physiotherapists aim to enhance the therapeutic context by taking care of general comfort (natural lighting, ventilation, heating). There are fewer answers on environmental design, appropriate architecture that respects privacy, and on the use of next-gen equipment. In clinical practice, regular use of CFs (i.e., relaxing music, soft light, comfort) with the best evidence-based treatment offers physiotherapists the opportunity to manage patients' symptoms; fear, avoidance, and anxiety are commonly related to musculoskeletal pain [11]. Current design patterns emphasize the therapeutic effects of appropriate design, what Rehn Schuster identified as the "placebo design effect" [46].

Almost all participants unanimously answered willingly to apply this topic further during practical training. This shows that even physiotherapists acknowledge the importance of this topic, which has developed in the literature over the last decade among physicians, as well as physiotherapy and nursing students $[5,6,8,46]$.

\section{Strengths and Weaknesses of the Study}

The methodological choice was a strong point, and is regarded as a useful tool for grasping the opinions and the perspectives of a large sample of healthcare workers. Other surveys have applied this methodological approach for placebo and nocebo effects and CFs $[4,7,8,25]$. This allowed us to extend our analysis. For the first time, a team of researchers individually analyzed each CF that is currently recognized.

The questions about Italian regions and universities of origin made it possible to draw up reports from a demographic point of view, seeking a future perspective for education.

A large number of answers came from private practice physiotherapists specialized in orthopedics (70.06\%). Their responses may not apply to physiotherapists specialized in other areas (e.g., neurological) and/or used in different contexts (e.g., hospitals). We deem this to be a point of weakness in the research. However, it may suggest future studies in this field. Furthermore, the way participants were asked how to define CFs with a closed question with four answer options could have given some preliminary insights to the participant, thus influencing their knowledge of the subject.

\section{Conclusions}

The responses to this survey show that Italian physiotherapists believe that the perception of pain and the success of their treatment also derive from the presence of positive CFs; however, the discrepancy between some answers shows the uncertainty of their conscious use, perhaps due to the complexity of the phenomenon. Most Italian physiotherapists assert that they do not use CFs on a daily basis, preferring verbal communication and a patient-centered approach. Otherwise, little attention is paid to the characteristics of the physiotherapist and to socially adequate environments to trigger placebo and nocebo effects. The research was useful in underlining the more widespread implementation of CFs in the musculoskeletal field, but less so for the other specializations. Future research should provide information on the difficulties that may hinder its adoption. The results of the research show how much it is necessary to enrich undergraduate and post-graduate study programs with these themes, to ensure the adequate use of the context. New implementation strategies must be brought into training courses so that as a student, it must be clear that the final result is always the combination of the specific effect of the treatment and the neurobiological effects caused by the variables related to the context. Future qualitative research should investigate the relationships between the determinants of patient satisfaction and expand the investigation into other physiotherapy settings to provide a thorough understanding of this topic. 
Supplementary Materials: All data generated or analyzed during this study are included in this published study. Other information of this study is available from the corresponding author on reasonable request. The following are available online at https:/ / www.mdpi.com/article/10.3390/healthcare9 060689/s1, Questionnaire: Knowledge and management of contextual factors: presentation and methodological premise.

Author Contributions: Conceptualization, M.B. and D.V.; Data curation, M.B.; Investigation, M.B., D.V., A.B., V.C; Methodology A.B.; Supervision, G.G.; Writing—original draft, M.B., D.V., A.B., V.C.; Writing-review and editing, G.G. All authors have read and agreed to the published version of the manuscript.

Funding: This research received no external funding.

Institutional Review Board Statement: Not applicable.

Informed Consent Statement: Informed consent was obtained from all subjects involved in the study.

Data Availability Statement: Not applicable.

Acknowledgments: The authors would like to thank all the Italian physiotherapists who took part in the survey.

Conflicts of Interest: The authors declare no conflict of interest.

\section{References}

1. Di Blasi, Z.; Harkness, E.; Ernst, E.; Georgiou, A.; Kleijnen, J. Influence of context effects on health outcomes: A systematic review. Lancet 2001, 357, 757-762. [CrossRef]

2. Carlino, E.; Frisaldi, E.; Benedetti, F. Pain and the context. Nat. Rev. Rheumatol. 2014, 10, 348-355. [CrossRef] [PubMed]

3. Carlino, E.; Benedetti, F. Different contexts, different pains, different experiences. Neuroscience 2016, 338, 19-26. [CrossRef]

4. Palese, A.; Rossettini, G.; Colloca, L.; Testa, M. The impact of contextual factors on nursing outcomes and the role of placebo/nocebo effects: A discussion paper. Pain Rep. 2019, 4, 1-9. [CrossRef] [PubMed]

5. Rossettini, G.; Palese, A.; Geri, T.; Fiorio, M.; Colloca, L.; Testa, M. Physical therapists' perspectives on using contextual factors in clinical practice: Findings from an Italian national survey. PLoS ONE 2018, 13, e0208159. [CrossRef] [PubMed]

6. Palese, A.; Cadorin, L.; Testa, M.; Geri, T.; Colloca, L.; Rossettini, G. Contextual factors triggering placebo and nocebo effects in nursing practice: Findings from a national cross-sectional study. J. Clin. Nurs. 2019, 28, 1966-1978. [CrossRef]

7. Rossettini, G. The knowledge of contextual factors as triggers of placebo and nocebo effects in patients with musculoskeletal pain: Findings from a national survey. Front. Psychiatry 2019, 10, 1-14. [CrossRef] [PubMed]

8. Cadorin, L.; Rossettini, G.; Testa, M.; Geri, T.; Palese, A. The awareness of contextual factors, placebo and nocebo effects among nursing students: Findings from a cross-sectional study. Nurse Educ. Pr. 2020, 42, 102670. [CrossRef]

9. Rossettini, G.; Carlino, E.; Testa, M. Clinical relevance of contextual factors as triggers of placebo and nocebo effects in musculoskeletal pain. BMC Musculoskelet. Disord. 2018, 19, 1-15. [CrossRef]

10. Rossettini, G.; Testa, M. Manual therapy RCTs: Should we control placebo in placebo control? Eur. J. Phys. Rehabil. Med. 2017, 54, 500-501.

11. Testa, M.; Rossettini, G. Enhance placebo, avoid nocebo: How contextual factors affect physiotherapy outcomes. Man. Ther. 2016, 24, 65-74. [CrossRef]

12. Eysenbach, G. Improving the Quality of Web Surveys: The Checklist for Reporting Results of Internet E-Surveys (CHERRIES). J. Med. Internet Res. 2004, 6, 1-6. [CrossRef] [PubMed]

13. Vandenbroucke, J.P. Strengthening the Reporting of Observational Studies in Epidemiology (STROBE): Explanation and elaboration. Epidemiology 2007, 18, 805-835. [CrossRef] [PubMed]

14. De Leeuw, D.; Hox, J.; Dillman, D. International Handbook of survey Methodology, 1st ed.; European Association of Methodology Series; Taylor and Francis Group: New York, NY, USA, 2008.

15. Team, R.C. A Language and Environment for Statistical Computing. Ind. Commer. Train. 2018, 1-16. [CrossRef]

16. David, F.N.; Cramer, H. Mathematical Methods of Statistics. Biometrika 1947, 34, 374. [CrossRef]

17. Revelle, A.W.; Revelle, M.W. Procedures for Psychological, Psychometric, and Personality; Northwestern University: Evanston, IL, USA, 2017.

18. Gómez-Rubio, V. ggplot2 Elegant Graphics for Data Analysis (2nd Edition). J. Stat. Softw. 2017, 77, 1-3. [CrossRef]

19. Rossettini, G.; Geri, T.; Palese, A.; Marzaro, C.; Mirandola, M.; Colloca, L.; Fiorio, M.; Turolla, A.; Manoni, M.; Testa, M. What Physiotherapists Specialized in Orthopedic Manual Therapy Know About Nocebo-Related Effects and Contextual Factors: Findings from a National Survey. Front. Psychol. 2020, 11, 582174. [CrossRef]

20. Pollo, A.; Carlino, E.; Benedetti, F. Placebo mechanisms across different conditions: From the clinical setting to physical performance. Philos. Trans. R. Soc. B: Biol. Sci. 2011, 366, 1790-1798. [CrossRef] 
21. Rossettini, G.; Camerone, E.M.; Carlino, E.; Benedetti, F.; Testa, M. Context matters: The psychoneurobiological determinants of placebo, nocebo and context-related effects in physiotherapy. Arch. Physiother. 2020, 10, 1-12. [CrossRef]

22. Ferreira, P.H.; Ferreira, M.L.; Maher, C.G.; Refshauge, K.M.; Latimer, J.; Adams, R.D. The Therapeutic Alliance Between Clinicians and Patients Predicts Outcome in Chronic Low Back Pain. Phys. Ther. 2013, 93, 470-478. [CrossRef]

23. Wager, T.D.; Atlas, L.Y. The neuroscience of placebo effects: Connecting context, learning and health. Nat. Rev. Neurosci. 2015, 16, 403-418. [CrossRef]

24. Trinderup, J.S.; Fisker, A.; Juhl, C.B.; Petersen, T. Fear avoidance beliefs as a predictor for long-term sick leave, disability and pain in patients with chronic low back pain. BMC Musculoskelet. Disord. 2018, 19, 1-8. [CrossRef] [PubMed]

25. Wells, R.E.; Kaptchuk, T.J. To Tell the Truth, the Whole Truth, May Do Patients Harm: The Problem of the Nocebo Effect for Informed Consent. Am. J. Bioeth. 2012, 12, 22-29. [CrossRef]

26. Oliveira, V.C.; Refshauge, K.M.; Ferreira, M.L.; Pinto, R.Z.; Beckenkamp, P.R.; Filho, R.F.N.; Ferreira, P.H. Communication that values patient autonomy is associated with satisfaction with care: A systematic review. J. Physiother. 2012, 58, 215-229. [CrossRef]

27. He, X.; Sun, Q.; Stetler, C. Warm Communication Style Strengthens Expectations and Increases Perceived Improvement. Heal. Commun. 2018, 33, 939-945. [CrossRef] [PubMed]

28. Sueki, D.G.; Dunleavy, K.; Puentedura, E.J.; Spielholz, N.I.; Cheng, M.S. The role of associative learning and fear in the development of chronic pain-A comparison of chronic pain and post-traumatic stress disorder. Phys. Ther. Rev. 2014, 19, 352-366. [CrossRef]

29. Brody, H.; Colloca, L.; Miller, F.G. The Placebo Phenomenon: Implications for the Ethics of Shared Decision-Making. J. Gen. Intern. Med. 2012, 27, 739-742. [CrossRef]

30. Petrie, K.J.; Rief, W. Psychobiological Mechanisms of Placebo and Nocebo Effects: Pathways to Improve Treatments and Reduce Side Effects. Annu. Rev. Psychol. 2019, 70, 599-625. [CrossRef] [PubMed]

31. Faasse, K.; Martin, L.R. The Power of Labeling in Nocebo Effects. Int. Rev. Neurobiol. 2018, 139, 379-406. [CrossRef]

32. Blasini, M.; Corsi, N.; Klinger, R.; Colloca, L. Inaugural Review Series Translational Pain Research Nocebo and pain: An overview of the psychoneurobiological mechanisms. PAIN Rep. 2017, 2, 1-9.

33. Miciak, M.; Mayan, M.; Brown, C.; Joyce, A.S.; Gross, D.P. The necessary conditions of engagement for the therapeutic relationship in physiotherapy: An interpretive description study. Arch. Physiother. 2018, 8, 1-12. [CrossRef] [PubMed]

34. Stenberg, G.; Fjellman-Wiklund, A.; Ahlgren, C. Getting confirmation: Gender in expectations and experiences of healthcare for neck or back patients. J. Rehabil. Med. 2012, 44, 163-171. [CrossRef] [PubMed]

35. Stenberg, G.; Ahlgren, C. A gender perspective on physiotherapy treatment in patients with neck and back pain. Adv. Physiother. 2010, 53, 1-7. [CrossRef]

36. Sivagurunathan, M.; MacDermid, J.; Chuang, J.C.Y.; Kaplan, A.; Lupton, S.; McDermid, D. Exploring the role of gender and gendered pain expectation in physiotherapy students. Can. J. Pain 2019, 3, 128-136. [CrossRef]

37. Defrin, R.; Shramm, L.; Eli, I. Gender role expectations of pain is associated with pain tolerance limit but not with pain threshold. Pain 2009, 145, 230-236. [CrossRef]

38. Bisconti, M.; Brindisino, F.; Maselli, F. Gender Medicine and Physiotherapy: A Need for Education. Findings from an Italian National Survey. Healthcare 2020, 8, 516. [CrossRef]

39. Iannello, P.; Mottini, A.; Tirelli, S.; Riva, S.; Antonietti, A. Ambiguity and uncertainty tolerance, need for cognition, and their association with stress. A study among Italian practicing physicians. Med. Educ. Online 2017, 22, 1270009. [CrossRef] [PubMed]

40. Dukhu, S.; Purcell, C.; Bulley, C. Person-centred care in the physiotherapeutic management of long-term conditions: A critical review of components, barriers and facilitators. Int. Pr. Dev. J. 2018, 8, 1-27. [CrossRef]

41. Geri, T.; Viceconti, A.; Minacci, M.; Testa, M.; Rossettini, G. Manual therapy: Exploiting the role of human touch. Musculoskelet. Sci. Pr. 2019, 44, 102044. [CrossRef]

42. Colloca, L.; Barsky, A.J. Placebo and Nocebo Effects. New Engl. J. Med. 2020, 382, 554-561. [CrossRef]

43. Bajcar, E.A.; Bąbel, P. How Does Observational Learning Produce Placebo Effects? A Model Integrating Research Findings. Front. Psychol. 2018, 9, 2041. [CrossRef] [PubMed]

44. Medina-Mirapeix, F.; Del Baño-Aledo, M.E.; Oliveira-Sousa, S.L.; Escolar-Reina, P.; Collins, S.M. How the Rehabilitation Environment Influences Patient Perception of Service Quality: A Qualitative Study. Arch. Phys. Med. Rehabil. 2013, 94, $1112-1117$. [CrossRef] [PubMed]

45. Rehn, J.; Schuster, K. Clinic Design as Placebo-Using Design to Promote Healing and Support Treatments. Behav. Sci. 2017, 7, 77. [CrossRef] [PubMed]

46. Evers, A.W.; Colloca, L.; Blease, C.; Annoni, M.; Atlas, L.Y.; Benedetti, F.; Bingel, U.; Büchel, C.; Carvalho, C.; Colagiuri, B.; et al. Implications of Placebo and Nocebo Effects for Clinical Practice: Expert Consensus. Psychother. Psychosom. 2018, 87, $204-210$. [CrossRef] [PubMed] 